\title{
Randomised controlled trial to examine the effects of a GP exercise referral programme in Hailsham, East Sussex,on modifiable coronary heart disease risk factors
}

Adrian H Taylor, Jo Doust, Nick Webborn

\begin{abstract}
Objective-To examine the effects of a GP exercise referral programme on modifiable coronary heart disease risk factors. Design-Randomised controlled trial. A battery of validated measures were carried out at $0,8,16,26$, and 37 weeks.

Setting-Two community health centres and a leisure centre in Hailsham, East Sussex.

Subjects-389 patients (smokers, hypertensive or overweight) were selected from medical records, screened for contraindications to exercise and 345 were invited into the study. Of 142 patients randomly allocated, $40(41 \%)$ completed the study in the exercise group and $31(69 \%)$ in the control group. Sixty (35\%) invited smokers $(48 \%$ of non-smokers), 71 (38\%) invited hypertensive patients $(45 \%$ of non-hypertensive patients), and 107 (45\%) overweight patients (33\% of non-overweight patients) were randomised. Of those randomised, $27(45 \%)$ smokers, 52 (48\%) overweight, and 43 (61\%) hypertensive patients completed the study. Intervention-The exercise group was offered 20, half price sessions over 10 weeks at a leisure centre. Patients engaged in moderate and vigorous aerobic type activity on various exercise machines, in a semi-supervised, informal environment. Results $-87 \%$ of those referred used the prescription and $28 \%$ (high adherers) $(45 \%$ of obese patients) did at least 15 sessions. The exercise group reduced sum of skinfolds by $8.1 \%$ (2.9 to $13.3,95 \%$ confidence intervals) more than the control group, up to 16 weeks after baseline. High adherers reduced sum of skinfolds by $9.2 \%(0.9$ to 17.5) more than the control group, up to 26 weeks. High adherers reduced systolic blood pressure by $7.2 \%(-0.7$ to 14.9$)$ (that is, $9 \mathrm{~mm} \mathrm{Hg}$ ) more than low adherers, up to 37 weeks. Non-smokers and obese patients attended more prescribed sessions than smokers and non-overweight patients.
\end{abstract}

2 December 1997

Table 1 Risk factor characteristics of sample invited into and recruited into the study

\begin{tabular}{lcccc}
\hline Recruitment & Smoker & BMI>25 & Hypertensive & Total \\
\hline Number invited & $174(100)$ & $239(100)$ & $188(100)$ & $345(100)$ \\
No response to two mailings & $63(36)$ & $71(30)$ & $56(30)$ & $105(30)$ \\
Replied but not interested & $51(29)$ & $61(25)$ & $61(32)$ & $98(28)$ \\
Number (\%) randomised & $60(35)$ & $107(45)$ & $71(38)$ & $142(41)$ \\
Number of study completers & $27(16)$ & $52(22)$ & $43(23)$ & $71(21)$ \\
$\quad$ & & & &
\end{tabular}

Risk factor determined from medical records. Percentages are shown in parentheses.
Conclusions-Reduction in sum of skinfolds was maintained up to 26 weeks, among high adherers compared with controls. Reduction in systolic blood pressure was evident up to 37 weeks among high adherers, but only in comparison with low adherers. Selection of appropriate referees and use of other strategies to improve exercise adherence will help to maximise the benefits from GP exercise prescription schemes.

(f Epidemiol Community Health 1998;52:595-601)

Physical inactivity has been identified as an endemic coronary heart disease (CHD) risk factor. ${ }^{1-5}$ Increasing physical activity in the population may also modify other risk factors such as body fat and hypertension. For example, in a review, ${ }^{6}$ net changes in systolic blood pressure, associated with endurance training, were reported to be -6.2 , and -9.9 $\mathrm{mm} \mathrm{Hg}$ among borderline hypertensive and hypertensive patients, respectively.

A growing interest has emerged in the promotion of physical activity through primary health care. $^{78}$ Many schemes involve GPs referring patients to leisure centre based exercise programmes. However, some scepticism is held by health service managers and others ${ }^{9}$ about the effectiveness of a programme of prescribed exercise for chronic health problems. Such schemes have not previously been rigorously evaluated in the UK. The purpose of this randomised controlled study was therefore to evaluate a fully operational GP referral scheme, in terms of modifying physical activity, blood pressure, smoking, and body composition over a nine month period.

\section{Methods}

SUBJECTS

Approval was obtained from the Eastbourne Health Authority Local Research Ethics Committee. A total of 345 men and women, aged 40-70, identified as smokers, hypertensive (that is, SBP/DBP at least $140 / 90 \mathrm{~mm} \mathrm{Hg}$ ) or overweight $(\mathrm{BMI}>25)$ on medical records, were mailed up to two invitations to participate (and information about the study) from their $\mathrm{GP} /$ research team. This followed the exclusion of 44 patients with SBP $>200 \mathrm{~mm} \mathrm{Hg}(\mathrm{n}=3)$, a history of myocardial infarction or angina pectoris $(n=8)$, diabetes mellitus $(n=4)$, a musculoskeletal condition that restricted physical activity $(n=9)$, and anyone who had previously 
been referred on the exercise prescription scheme $(n=20)$. Existing funding contracts between the health services and leisure services did not permit high risk patients to be referred.

Table 1 shows details of subject recruitment and completion of the study protocol. Nonresponse bias was examined by comparing the $\mathrm{CHD}$ risk factor profile (from health centre medical records) of those entering the study with those who did not. There was no sex or age bias, but smokers were significantly less likely than non-smokers to enter the study. However, the overweight ( $45 \%)$ were significantly more likely to enter the study than nonoverweight patients (33\%). Overall, 240 (70\%) of the 345 invited to enter the study responded, but disappointingly, this recruitment method resulted in only 142 (41\%) actually being randomised. Findings are reported elsewhere in more detail. ${ }^{10}$

\section{STUDY PROTOCOL}

Patients completed an initial assessment, conducted by a trained assessor, at one of two health centres, within two miles of the leisure centre. Randomisation, using a random numbers table, took place at the end of the first assessment, with a 7:3 greater likelihood of being referred into the exercise programme compared with the control group, to offset anticipated non-adherence to the exercise programme. Both exercise and control group subjects were given Health Education Authority leaflets on preventing CHD but were given no specific advice to change their lifestyle. Subjects were subsequently contacted by phone to arrange assessments at mid-intervention, and post-intervention, and three and six months later. It was emphasised throughout the study that attending the assessments should be maintained irrespective of the level of adherence to the exercise programme. All subjects in the control group were offered a referral to the leisure centre at the end of the final assessment.

THE EXERCISE REFERRAL PROGRAMME

Patients were given a signed prescription card, with a reason for referral, resting heart rate and blood pressure, intensity of recommended exercise (three levels), and prohibited activity. They were instructed to take it to Hailsham Lagoon Leisure Centre, East Sussex, and arrange an appointment for an introductory session to start a 10 week programme with up to 20 sessions at $£ 1.30$ each (that is, half the normal admission price). The introductory session entailed a simple lifestyle assessment, a brief discussion about exercise perceptions and goals, an assessment of blood pressure, weight and height, and advice on use of the cycle ergometers, rowing machines, treadmills, stair climbing machines, and patient record cards. Patients were encouraged to progressively increase the duration and intensity of exercise during the referral period. Supervision was available when requested but patients attended informally between 9 am and $5 \mathrm{pm}$ on weekdays, usually for up to an hour. A mid and end of programme individual assessment were the only formal sessions, though attendance was recorded by leisure centre staff. Staff were not openly made aware of which patients had been referred as part of the study to limit any preferential treatment. Up to 30 new patients per week were being referred to the scheme by over 70 GPs during the study.

\section{OUTCOME MEASURES}

Blood pressure and anthropometric measures were taken by a trained researcher at baseline, and at 16, 26, and 37 weeks. Systolic and diastolic blood pressure were measured from the right arm while the subject was seated, after about 20 minutes of the interview, using a random zero sphygmomanometer (Cranlea) to avoid digit preference. Body weight and height were measured without heavy clothes or shoes and used to calculate body mass index (BMI). Skinfold measures were taken using Harpenden skinfold calipers. Two measures were taken at each site and an average calculated for subscapular, suprailiac, triceps and biceps. ${ }^{11}$ The sum of four skinfolds was derived.

At each assessment a questionnaire was used to assess smoking behaviour, physical activity, and medication use, and open-ended perceptions of the exercise programme (only at eight weeks). Physical activity was assessed using Blair's seven day recall method. ${ }^{12-16}$ An approximation of energy expenditure was determined from minutes spent in light, moderate, and vigorous activity. ${ }^{12}$ Data on adherence to the exercise programme were obtained from computerised leisure centre records. Medical records were consulted to determine the number of visits to the GP in the 12 months before referral and also during the nine month study.

\section{DATA ANALYSIS}

Changes in blood pressure, anthropometric characteristics, lifestyle, and health service usage were compared between the control group and exercise group. Analysis of covariance (ANCOVA) was used where baseline measures differed between the groups with results reported as adjusted means. The study sample was large enough to detect a difference in blood pressure of $4 \mathrm{~mm} \mathrm{Hg}$ systolic with a power of 0.90 and a two sided p value of 0.05 . Further analyses examined the effects of study incompletion and exercise adherence.

\section{Results}

COMPLETION OF THE STUDY PROTOCOL Of the 142 patients randomised, 71 (50\%) provided data at all assessments, including 27 (45\%) smokers, 52 (48\%) overweight patients, and $43(61 \%)$ hypertensive patients (at baseline) (see table 1). Randomisation of 142 subjects to the exercise $(n=97)$ and control $(n=45)$ groups established comparable baseline 
Table 2 Baseline characteristics of patients in exercise and control group who entered and who completed all assessments. Except where stated values are means (SEM)

\begin{tabular}{llllll}
\hline & All subjects & & & Study completers \\
\cline { 2 - 3 } \cline { 5 - 6 } Variable & $\begin{array}{l}\text { Exercise group } \\
(n=97)\end{array}$ & $\begin{array}{l}\text { Control group } \\
(n=45)\end{array}$ & & $\begin{array}{l}\text { Exercise group } \\
(n=40)\end{array}$ & $\begin{array}{l}\text { Control group } \\
(n=31)\end{array}$ \\
\hline Age (y) & $54.1(0.8)$ & $54.4(1.3)$ & & $54.6(1.2)$ & $55.2(1.7)$ \\
Men/women & $36 / 61$ & $17 / 28$ & & $19 / 21$ & $13 / 18$ \\
Minutes of moderate activity (past week) & $138.6(21.3)$ & $147.8(37.9)$ & & $231.3(44.7)^{\star}$ & $116.8(36.5)^{\star}$ \\
Minutes of vigorous activity (past week) & $6.1(2.6)$ & $23.7(20.0)$ & & $7.8(4.5)$ & $4.6(2.7)$ \\
No (\%) doing mod/vig activity (past week) & $56(58 \%)$ & $28(62 \%)$ & & $28(78 \%)$ & $19(61 \%)$ \\
Energy expenditure (kcal/kg/day) & $33.8(0.2)$ & $33.8(0.4)$ & & $34.3(0.3)^{\star}$ & $33.5(0.3)^{\star}$ \\
Systolic blood pressure (mm Hg) & $132.2(1.9)$ & $134.6(2.8)$ & & $136.7(2.3)$ & $136.9(3.5)$ \\
Diastolic blood pressure (mm Hg) & $86.1(1.2)$ & $86.2(1.7)$ & & $86.8(1.6)$ & $88.4(2.2)$ \\
Body weight (kg) & $77.3(1.3)$ & $75.4(1.9)$ & & $80.3(2.0)^{\star}$ & $75.3(13.0)^{\star}$ \\
Body mass index (kg/m×m) & $27.9(0.4)$ & $27.0(0.5)$ & & $28.7(0.6)^{\star}$ & $26.7(0.6)^{\star}$ \\
Sum of 4 skinfolds (mm) & $76.5(2.8)$ & $70.8(3.5)$ & & $85.1(4.7)^{\star \star}$ & $66.9(3.4)^{\star \star}$ \\
Waist-hip ratio & $0.87(.01)$ & $0.86(.02)$ & & $0.88(.01)$ & $0.85(.02)$ \\
No of visits to GP (past year) $\dagger$ & $5.9(0.6)$ & $5.1(0.6)$ & & $6.3(1.0)$ & $5.8(0.7)$ \\
No (\%) of smokers & $42(43 \%)$ & $18(40 \%)$ & & $15(38 \%)$ & $12(39 \%)$ \\
No (\%) overweight (BMI=25-29.9) & $51(53 \%)$ & $24(53 \%)$ & & $18(45 \%)$ & $18(58 \%)$ \\
No (\%) obese (BMI>29.9) & $29(30 \%)$ & $8(18 \%)$ & & $17(43 \%)$ & $4(13 \%)$ \\
\hline
\end{tabular}

Difference between exercise and control groups ${ }^{\star} \mathrm{p}<0.05,{ }^{\star \star} \mathrm{p}<0.01$; †data from medical records.

measures (see table 2). Forty patients (41\%) in the exercise group and $31(69 \%)$ of the control group completed all assessments. Among study completers, the exercise group did significantly more moderate leisure time activity, expended more energy, and had greater sum of skinfolds, body weight, and BMI than the controls (see table 2), at baseline.

ADHERENCE TO THE EXERCISE PROGRAMME Available leisure centre data for 95 referred patients revealed a mean attendance rate of 9.1 sessions $(\mathrm{SD}=7.2)$, of the 20 prescribed. Table 3 shows the number of patients, overall, and by risk group (see Determinants of Exercise Adherence later) who attended none, at least 5, 10,15 , and all prescribed sessions.
OUTCOME MEASURES

Physical activity

ANCOVA, controlling for baseline values, revealed differences in energy expenditure, between the groups at eight and 16 weeks (see table 4 for adjusted means). The exercise group did significantly more moderate activity up to eight weeks, and more vigorous activity up to 16 weeks. Between baseline and 26 weeks, $15 \%$ more referred patients did at least some weekly moderate/vigorous activity while there was no change in the control group. No change was evident for either group at 37 weeks.

\section{Anthropometry and blood pressure}

ANCOVA, controlling for baseline values, revealed a significant difference in sum of

Table 3 Adherence to exercise programme among all referees and by risk group

\begin{tabular}{lccccc}
\hline Patients referred & $\begin{array}{l}\text { Smoker 41 } \\
(100 \%)\end{array}$ & $\begin{array}{l}\text { Overweight 49 } \\
(100 \%)\end{array}$ & $\begin{array}{l}\text { Obese 29 } \\
(100 \%)\end{array}$ & $\begin{array}{l}\text { Hypertensive 44 } \\
(100 \%)\end{array}$ & $\begin{array}{l}\text { Total 95 } \\
(100 \%)\end{array}$ \\
\hline $\begin{array}{l}\text { Sessions attended } \\
\text { Attended 0 sessions }\end{array}$ & $9(22)$ & $6(12)$ & $1(3)$ & $3(7)$ & $12(13)$ \\
Attended at least 5 sessions & $20(49)$ & $29(59)$ & $28(97)$ & $34(77)$ & $65(68)$ \\
Attended at least 10 sessions & $13(32)$ & $15(31)$ & $18(62)$ & $20(45)$ & $39(41)$ \\
Attended at least 15 sessions & $9(22)$ & $11(22)$ & $13(45)$ & $14(32)$ & $27(28)$ \\
Attended all prescribed sessions & $5(12)$ & $6(12)$ & $8(28)$ & $10(23)$ & $16(17)$ \\
\hline
\end{tabular}

Overweight (BMI 25-29.9); obese (BMI=>30). Percentages are shown in parentheses.

Table 4 Physical activity, SBP, DBP, BMI, and sum of skinfold for exercise and control group who completed all assessments. Figures are means (SEM) adjusted for baseline values at 8, 16, 26, and 37 weeks

\begin{tabular}{llllll}
\hline Variable & Group & Week 8 & Week 16 & Week 26 & Week 37 \\
\hline Moderate (min/wk) & Exercise & $247(29)$ & $226(41)$ & $183(39)$ & $158(38)$ \\
& Control & $145(32)$ & $160(47)$ & $206(45)$ & $162(44)$ \\
& $\star$ & $\mathrm{p}=0.02$ & $\mathrm{p}=\mathrm{NS}$ & $\mathrm{p}=\mathrm{NS}$ & $\mathrm{p}=\mathrm{NS}$ \\
Vigorous (min/wk) & Exercise & $49(10)$ & $59(12)$ & $56(18)$ & $42(16)$ \\
& Control & $21(11)$ & $21(13)$ & $34(20)$ & $23(19)$ \\
& $\star$ & $\mathrm{p}=0.06$ & $\mathrm{p}=0.03$ & $\mathrm{p}=\mathrm{NS}$ & $\mathrm{p}=\mathrm{NS}$ \\
Energy expended (kcal/kg/day) & Exercise & $34.6(0.2)$ & $34.6(0.2)$ & $34.4(0.3)$ & $34.1(0.4)$ \\
& Control & $33.7(0.3)$ & $33.9(0.3)$ & $34.3(0.4)$ & $33.9(0.4)$ \\
& $\star$ & $\mathrm{p}=0.01$ & $\mathrm{p}=0.08$ & $\mathrm{p}=\mathrm{NS}$ & $\mathrm{p}=\mathrm{NS}$ \\
$\mathrm{SBP}(\mathrm{mm} \mathrm{Hg})$ & Exercise & $\mathrm{n} / \mathrm{a}$ & $130.0(2.3)$ & $129.7(2.2)$ & $129.7(2.7)$ \\
& Control & $\mathrm{n} / \mathrm{a}$ & $129.6(2.6)$ & $130.6(2.6)$ & $131.3(3.2)$ \\
& $\star$ & & $\mathrm{p}=\mathrm{NS}$ & $\mathrm{p}=\mathrm{NS}$ & $\mathrm{p}=\mathrm{NS}$ \\
DBP $(\mathrm{mm} \mathrm{Hg})$ & Exercise & $\mathrm{n} / \mathrm{a}$ & $83.9(1.2)$ & $83.6(1.3)$ & $84.7(1.5)$ \\
& Control & $\mathrm{n} / \mathrm{a}$ & $83.8(1.5)$ & $83.5(1.5)$ & $83.3(1.7)$ \\
BMI $(\mathrm{kg} / \mathrm{m} \times \mathrm{m})$ & $\star$ & $\mathrm{p}=\mathrm{NS}$ & $\mathrm{p}=\mathrm{NS}$ & $\mathrm{p}=\mathrm{NS}$ \\
& Exercise & $\mathrm{n} / \mathrm{a}$ & $27.5(0.1)$ & $27.3(0.2)$ & $27.5(0.2)$ \\
& Control & $\mathrm{n} / \mathrm{a}$ & $27.6(0.1)$ & $27.5(0.2)$ & $27.6(0.2)$ \\
Sum of skinfolds $(\mathrm{mm})$ & $\star$ & $\mathrm{p}=\mathrm{NS}$ & $\mathrm{p}=\mathrm{NS}$ & $\mathrm{p}=\mathrm{NS}$ \\
& Exercise & $\mathrm{n} / \mathrm{a}$ & $70.3(1.3)$ & $69.9(1.8)$ & $71.0(2.1)$ \\
& Control & $\mathrm{n} / \mathrm{a}$ & $75.7(1.4)$ & $74.9(2.0)$ & $76.3(2.3)$ \\
& $\star$ & & $\mathrm{p}<0.01$ & $\mathrm{p}=0.08$ & $\mathrm{p}=0.09$ \\
\end{tabular}

${ }^{\star} \mathrm{p}$ Value for difference between adjusted means; $\mathrm{n} / \mathrm{a}=$ not assessed.

Exercise group $(n=40)$, control group $(n=31)$, except for activity measures ( $n=36$, exercise group). 
Table 5 Pairwise comparisons between high $(n=23)$ and low $(n=17)$ exercise adherers and control group $(n=31)$, who completed all assessments

Mean differences (95\% confidence intervals) $\dagger$

\begin{tabular}{llll} 
Comparison & SBP $(\mathrm{mm} \mathrm{Hg})$ & BMI & Sum of skinfolds \\
\hline At 16 weeks: & & & \\
High adherers $v$ low adherers & $0.42(-6.69$ to 7.53$)$ & $1.19(-0.64$ to 3.02$)$ & $6.35(-0.27$ to 12.97$)$ \\
High adherers $v$ control & $0.19(-5.97$ to 6.35$)$ & $1.21(-0.36$ to 2.79$)$ & $11.08(5.39 \text { to } 16.77)^{\star}$ \\
Low adherers $v$ control & $0.23(-6.52$ to 6.98$)$ & $0.02(-1.70$ to 1.75$)$ & $4.73(-1.52$ to 10.97$)$ \\
At 26 weeks: & $6.95(-0.03 \text { to } 13.94)^{\star}$ & $2.55(-0.37 \text { to } 4.72)^{\star}$ & $6.66(-3.09$ to 16.41$)$ \\
High adherers $v$ low adherers & $3.98(-2.07$ to 10.03$)$ & $2.05(-0.18 \text { to } 3.93)^{\star}$ & $9.18(0.91 \text { to } 17.45)^{\star}$ \\
High adherers $v$ control & $2.97(-3.66$ to 9.59$)$ & $0.49(-1.56$ to 2.55$)$ & $2.52(-6.61$ to 11.66$)$ \\
Low adherers $v$ control & & & \\
At 37 weeks: & $7.15(-0.69 \text { to } 14.99)^{\star}$ & $1.33(-1.39$ to 4.04$)$ & $3.55(-6.61$ to 13.69$)$ \\
High adherers $v$ low adherers & $4.55(-2.24$ to 11.35$)$ & $0.86(-1.48$ to 3.19$)$ & $5.85(-2.89$ to 14.58$)$ \\
High adherers $v$ control & $2.59(-4.85$ to 10.04$)$ & $0.47(-2.09$ to 3.03$)$ & $2.30(-7.28$ to 11.88$)$ \\
Low adherers $v$ control & & &
\end{tabular}

†Of difference between adjusted means; ${ }^{\star} \mathrm{p}<0.05$.

skinfolds at 16 weeks with an $8.1 \%$ (95\% confidence intervals 2.9 to 13.3 ) greater reduction in the exercise group than the control group (see table 4 for adjusted means). No differences were seen in blood pressure.

Other outcome variables

Referral to the exercise programme seemed to have no impact on smoking behaviour, number of patients taking hypertensive medication, or number of visits to the GP.

EFFECTS OF EXERCISE PROGRAMME ADHERENCE Analyses were also conducted to examine the effects of adherence to the 10 week exercise programme. A median split led to the classification of exercise adherers as low (less than 15 sessions attended) or high (15 or more sessions) adherers. At 26 weeks, sum of skinfolds was reduced by $10.3 \%$ (high adherers, $n=23$ ), $3.7 \%$ (low adherers, $n=17$ ) and $1.1 \%$ in the control group $(n=31)$. At 26 weeks, BMI was reduced by $2.7 \%$ (high adherers), $0.2 \%$ (low adherers), and $0.7 \%$ (control group). At 37 weeks SBP was reduced by $8.1 \%$ (high adherers), $0.9 \%$ (low adherers) and 3.6\% (control group). Table 5 shows the pairwise comparisons and those that were significantly different. In comparison with the control group, reductions among the high adherers were significantly greater for BMI and sum of skinfolds at 26 week. In comparison with low adherers, reductions in SBP were significantly greater among high adherers at 26 and 37 weeks.

DETERMINANTS OF EXERCISE ADHERENCE

Adherence was not related to age, sex, employment status and occupational type, marital and family status, attained educational level, and housing type (that is, owner occupier, renter, etc). Table 3 shows the proportion for each risk category who attended none, at least five, 10, 15, and all prescribed sessions. Patients at baseline who were non-smokers, obese, had a greater hip circumference and sum of skinfolds, and were more moderately active were more likely to adhere. Smokers attended 6.7 $(\mathrm{SD}=7.3)$ and non-smokers attended 10.8 sessions $(\mathrm{SD}=6.7), t=2.84, \mathrm{p}<0.01 .45 \%$ of those with a BMI of greater than 30 (obese) were high adherers. Only the amount of moderate intensity activity (in the previous week) at baseline was related to adherence, $F$ (1, $93)=8.72, p<0.01$, with $7 \%$ of the variance explained. Further regression analysis showed significant relations between exercise adherence and baseline measures of weight, $F$ ( 1 , $93)=5.28, \mathrm{p}<0.05, r^{2}=5 \%$, sum of skinfolds, $F$ $(1,92)=11.65, \mathrm{p}<0.01, r^{2}=11 \%$, and hip circumference, $F(1,80)=15.95, \mathrm{p}<0.0001$, $r^{2}=17 \%$.

Interviews with referred patients at eight weeks identified about $50 \%$ were positive, $35 \%$ had mixed feelings, and $15 \%$ had only negative comments about the concept of GP referral to a leisure centre based exercise programme. A variety of concerns were raised about the programme, which were more common among low adherers including the following: long waiting time before the introductory session (up to five weeks); lack of staff support in a sometimes crowded and noisy exercise room; and inconvenient times (during off peak hours, 9 am-5 pm) for referred patients.

IMPLICATIONS OF STUDY NON-COMPLETION

Among the control group, there was no observable difference in outcome variable change from baseline, between study completers and non-completers. Among the exercise group, the 40 study completers had a higher mean exercise programme attendance $(M=14.5, \quad S E M=0.9)$ than the 55 study non-completers $(M=5.9, S E M=0.8), F(1$, $93)=47.8, \mathrm{p}<0.001$. From available data, change in all outcome variables among study non-completers, (for example, from 23 patients providing SBP data at baseline and 16 weeks), tended to parallel changes among the low exercise adherence group. ${ }^{10}$

\section{Discussion}

EXERCISE PROGRAMME ADHERENCE

The exercise adherence rates were similar to the few, non-experimental, evaluations of such schemes in the UK. For example, a $22 \%$ programme completion rate (among 729 patients referred for a variety of long term physical and psychological conditions) was reported by Wealden District Council ${ }^{17}$ and conducted at the same time as the present study. In one other study, ${ }^{18} 40 \%$ did not attend the initial session of a multi-centred exercise referral programme, and $20 \%$ who were prescribed 
exercise were exercising after 10 weeks. The uptake of the exercise prescription in the present study (87\%) was encouraging.

It is essential to identify the determinants of adherence to examine the potential for CHD risk change among different groups. In this study, less active patients and smokers at baseline had lower adherence to the programme. However, it was particularly encouraging to note that obese patients were more motivated to comply with the exercise programme, in light of recent reports of decreasing activity and increasing obesity in the population. ${ }^{19}$ This is in contrast with previous findings that suggested that those with greater body weight and body fat adhered less to exercise programmes. ${ }^{20}$

EFFECTS OF REFERRAL

Referral to the exercise programme led to largely short-term increases in physical activity, and reductions in sum of skinfolds, and blood pressure. The most notable changes were dependent on adherence to the programme. The reductions of up to $9.6 \mathrm{~mm} \mathrm{Hg}(7 \%)$ in mean SBP (at 37 weeks), among high adherers are within the expected range from the literature, given the broad range of baseline levels of hypertension in this study. ${ }^{6}$ Reviews of randomised trials without exercise interventions indicate that similar changes reduce the relative risk of stroke by about $35-40 \%$ and of CHD by $15-20 \%$.

Anecdotal evidence had suggested that there would be reductions in smoking, medication use, and visits to the GP, among referred patients. This study did not support such reports, possibly because of the nature of the referral scheme, at the time. Exercise counselling did not attempt to highlight the potential for exercise as an adjunct to other smoking cessation strategies or as an aid to coping with smoking withdrawal symptoms. Also, the limited liaison between health and leisure service personnel after referral, at the time of data collection, probably resulted in GPs missing the opportunity to "reward" some appropriate patients with reduced medication in response to lower blood pressure.

These effects of the referral programme could be viewed as rather disappointing but should be considered in light of a number of important issues.

EXERCISE REFERRAL SCHEMES: IMPORTANT ISSUES Since the conception of GP exercise referral schemes involving leisure centre based programmes, little scientific information has become available about the likely adherence rates and determinants. One factor to consider is the size of the scheme or number of referrals to a specific leisure centre. A recent audit ${ }^{17}$ supported the notion that smaller schemes, offering more individualised supervision of referees, have higher adherence rates. The trade off is that small schemes have less impact on public health and have higher costs per patient.

It may be argued that even larger schemes may have little impact on public health. However, in a community like Hailsham, in East Sussex, with 50 GPs referring patients

\section{KEY POINTS}

- There has been no previous randomised controlled trials to evaluate the effectiveness of a leisure centre based GP exercise prescription schemes in the UK.

- There was a mean attendance at the leisure centre of nine of 20 sessions with $28 \%$ ( $45 \%$ of obese patients) completing at least $75 \%$ of the sessions.

- Six months after the 10 week programme, systolic blood pressure was significantly reduced among the high adherers compared with low adherers.

- GP exercise referral schemes can help to reduce hypertension, body weight, and body fat but further refinements are necessary to maximise their potential.

- This study highlighted the complexities of conducting a randomised controlled trial of a fully operational community based exercise programme.

into the scheme, it has been estimated that at least $10 \%$ of the population has experienced the exercise referral programme, over a period of six years. Ongoing media attention, and contact by the person referred with other members of the community, is likely to have substantially increased awareness of the potential benefits of physical activity. There has been little difficulty in recruitment, with invariably a two to three week waiting list to get onto the exercise programme after referral.

Over a 12 month period in 1996/7, East Sussex, Brighton and Hove Health Authority paid $£ 70000$ in subsidy for 1800 patients to attend 10 leisure centres. While this calculates at an average of under $£ 40$ per person referred, the average cost to the health authority for a patient completing at least $75 \%$ of the prescribed 20 sessions was calculated as $£ 75$. This assumed a $45 \%$ completion rate that recent audits support (personal communication, Robertson D). ${ }^{21}$ Importantly, the marginal cost for an extra adherer was calculated as $£ 25$. Clearly, any contract between health and leisure services on a purchaser-provider basis must accommodate variations in number of patients referred and completion rates, to motivate centres to maximise adherence and thereby increase the likelihood of CHD risk reduction. Lord and Green ${ }^{18}$ attempted to show the costs of a referral scheme but such calculations are not simple, especially when varying numbers of non-referred clients are also using the exercise facilities at the same time as referred patients. An attempt at a costhealth benefit or cost effectiveness analysis would certainly seem premature until we know more about adherence rates for different referral categories.

This study identified that adherence rates were higher among the obese and nonsmokers, which has implications for selecting patients for referral. In two reports by Wealden District Council, ${ }^{17}{ }^{21}$ completion rates across GPs referring at least 20 patients, during the 
seven and six month audits, varied from $5-44 \%$ and $28-54 \%$, respectively. The degree of commitment or enthusiasm by the GP, their understanding of the scheme and appropriate referral categories, and their interpersonal skills or style would all seem to be important though further research is necessary to identify the processes involved. Retrospective reasons given for low adherence to and satisfaction with GP exercise referral programmes seem to particularly focus on the quality of supervision. ${ }^{101721}$ This may be related to the rate of referral into a scheme and programme congestion but also the perceived interest shown by staff. If GP exercise referral schemes are seen as a form of alternative therapy then staff may have to adjust their roles in an leisure centre to a more client centred counselling approach. Long term dependence on staff may not be desirable though.

The increase in mean completion rate from $22 \%$ to $43 \%$, for 729 and 627 referred patients, respectively, ${ }^{17}{ }^{21}$ provides some cross sectional evidence that GP referral schemes can become more effective in retaining patients. The increase in programme adherence may well be because of the changes that East Sussex have implemented within their GP referral schemes (though further studies with control groups are needed). Such changes include the following: a university accredited training programme (involving medical, physical, psychological, and auditing aspects) for all leisure centre staff involved with the people referred; a training module and handbook for participating GPs and health professionals, with regular contact from a medical advisor and scheme coordinator $^{22}$; the health authority required a quarterly audit of completion rates by all subsidised leisure centre exercise programmes (derived from data collected on standardised computer software); health authority funding based on initial consultations and also incentive payments for programme completion; better liaison between the leisure centre staff and referring GP; a shift toward more specific referral categories and an emphasis on secondary prevention with higher (moderate) risk patients, as expertise develops in leisure centres.

Clearly, further longitudinal studies are necessary to identify changes in both semisupervised and free living physical activity: increases in programme adherence may not necessarily result in long term physical activity. The findings from this study would suggest that with greater programme adherence, the reductions in CHD risk will become even more evident among referred patients. With leisure centres widely available in the UK, GP exercise referral schemes may offer a unique opportunity to increase physical activity, with associated health benefits, under semi-supervised conditions, particularly among patients with existing diseased states such as moderate hypertension. There is an important educational component within GP referral schemes that contrasts with opportunistic advice giving or counselling in the primary health care setting. While the focus is on exercise perceptions, knowledge enhancement and experien- tial learning about responses to exercise, additional guidance about lifestyle and well being can be added to an exercise programme with low marginal costs in a leisure centre.

This study has involved an evaluation of a fairly basic model of exercise on prescription. Suggestions have been made about refining that model with recommendations for evaluation of a variety of factors that may influence programme adherence. There is also a need to identify and evaluate the effectiveness of additional practices such as, follow up telephone calls from the leisure centre and follow up exercise sessions (for example, walking) in groups outside the leisure centre.

\section{METHODOLOGICAL ISSUES}

Recent debate has concerned the appropriateness of randomised clinical trials ${ }^{23}$ in health services research and past reviewers have identified the potential problems. ${ }^{24}$ This study also encountered methodological problems; most notably there was a self selection bias in the sampling procedures and completion of the study. As might have been expected ${ }^{25}{ }^{26}$ smokers were less likely to enter the study, but surprisingly, overweight patients were more likely to enter. Similar bias occurred in terms of those completing the study, and analyses also revealed that those initially more active were more likely to complete the study. The effects of these biases was estimated from all available data, ${ }^{10}$ but clearly motivation to participate in this study (and intervention) was problematic. The researchers initially considered the use of incentives (for example, entry into a lottery) for patients entering and completing the study but it was felt that this would have influenced adherence to the exercise referral programme being evaluated. Opportunistic recruitment (rather than through mailed invitations) of patients attending primary health care settings, coupled with tailored motivational strategies to remain in the study may well have been more effective. These approaches add cost to evaluation and perhaps an unknown impact on the intervention effectiveness.

However, the strengths of this study are as follows: that the exercise intervention was part of a pre-existing community scheme; concurrent objective data from a much larger sample adds support to the generalisability of the findings ${ }^{17}$; the assessments took place under controlled conditions in a health centre; assessments over nine months provided important information about changes in outcome measures not previously available; this was the first evaluation of such a scheme with a randomised control group.

In conclusion, the exercise referral programme was effective in reducing sum of skinfolds and increasing vigorous physical activity, up to 16 weeks. Three months after the exercise programme, high adherers showed a significant reduction in BMI and sum of skinfolds, compared with the control group. Six months after the exercise programme, high adherers showed a significant reduction in SBP, compared with low adherers but not the control group. Effective moderation of $\mathrm{CHD}$ risk 
factors requires a focus on optimising adherence to the initial prescription and then promoting continued activity. Strategies should include, among a variety of possible refinements, careful selection of referees by the GP, exercise and health counselling at the leisure centre by trained staff, and an effective mechanism for health-leisure centre liaison during and after the period of prescription. Funding: we thank The South Thames Regional Health
Authority Primary Care Development Fund (Project 2/93) for Authority

The final project Steering Group involved: Hugh Graham, The final project Steering Group involved: Hugh Graham, David Robertson, Heidi-Mai Talbot, Adrian Taylor (Chair), Professor Alan Tomlinson, Stephanie Wadlow and Val Williamson, with statistical guidance from Liz Cheek and Richard Castle. We are grateful to the patients and staff at the Vicarage Fields and Quintin Health Centres, Hailsham, who supported
the study. Thanks also to Stuart Biddle, Ken Fox, Mark Shaw, the study. Thanks also to Stuart Biddle, Ken Fox, Mark Shaw, the paper.

1 Blair SN. Physical activity, fitness and coronary heart disease. In: Bouchard C, Shephard RJ, Stephens T. eds Physical activity, fitness and health: consensus statement. Champaign, Il: Human Kinetics 1994: 579-90.

2 Fentem PH. Benefits of exercise in health and disease. $B M \mathcal{F}$ 1994;308:1291-5

3 Department of Health. The health of the nation: coronary heart disease and stroke. London: HMSO, 1995.

4 Health Education Authority. Health update 5: Physical activity. London: HEA, 1995.

5 Morris JN. Exercise in the prevention of coronary heart disease: today's best buy in public health. Med Sci Sports Exerc 1994;26:807-14.

6 Fagard RH, Tipton CM. Physical activity, fitness, and hypertension. In: Bouchard C, Shephard RJ, Stephens T, hypertension. In: Bouchard C, Shephard RJ, Stephens T, eds. Physical activity, fitness and health: consensus

7 Biddle S, Fox K, Edmunds L. Physical activity promotion in primary health care in England. London: Health Education Authority, 1994.

8 Hillsdon M, Thorogood M, Anstiss T, et al. Randomised controlled trials of physical activity promotion in free living populations: a review. F Epidemiol Community Health 1995 49:448-53.
9 Iliffe S, See Tai S, Gould $M$, et al. Prescribing exercise in general practise. BMF 1994;309:494-5.

10 Taylor AH. Evaluating GP referral schemes: findings from a randomised controlled study. Chelsea School Topic Report no 6. Brighton: University of Brighton, 1996.

11 Durnin JVGA, Wormersley J. Body fat assessed from total body density and its estimation from skinfold thickness: measurements on 481 men and women aged from 16 to 72 years. Br 7 Nutr 1974; 32:77-97.

12 Blair SN. How to assess exercise habits and physical fitness. In: Matarazzo JD, Weiss SM, Herd AA, et al, eds. In: Matarazzo JD, Weiss SM, Herd AA, et al, eds.
Behavioural health: a handbook of health enhancement and Behavioural health: a handbook of health enhancement
disease prevention. New York: J Wiley, 1984: 424-47.

13 Dishman RK, Steinhardt M. Reliability and concurrent validity for a 7-day recall of physical activity in college students. Med Sci Sports Exerc 1988;20:14-25.

14 Miller DJ, Freedson PS, Kline GM. Comparison of activity levels using the Caltrac accelerometer and five questionnaires. Med Sci Sports Exerc 1994;26:376-82.

15 Paffenbarger RS, Blair, SN, Lee I-M, et al. Measurement of physical activity to assess health effects in free-living populations. Med Sci Sports Exerc 1993;25:60-70.

16 Taylor CB, Coffey T, Berra K, et al. Seven-day recall activity and self-report compared to a direct measure of physical activity. Am f Epidemiol 1984;120:818-24.

17 Wealden District Council. The Oasis Programme Evaluation Report. Hailsham, E Sussex: Wealden District Council Leisure Services, 1995.

18 Lord JC, Green F. Exercise on prescription: does it work? Health Educ F 1995;54:453-64.

19 James WPT. A public health approach to the problem of obesity. Int f Obes 1995;19 (suppl 3):S37-45.

20 Dishman RK. Advances in exercise adherence. Champaign, Il: Human Kinetics, 1995.

21 Wealden District Council. Programme evaluation report. Hailsham, E Sussex:Wealden District Council Leisure Services, 1996.

22 Webborn ADJ. Exercise on Prescription GP Referral Schemeshandbook for general practitioners. Brighton: East Sussex, Brighton and Hove HA, 1996.

23 McQuay H, Moore A. Need for rigorous assessment of palliative care. $B M F$ 1994;309:1315-16.

24 Fielder H, Shorney S, Wright D. Lessons from a pilot study on prescribing exercise. Health Educ f 1995;54:445-52.

25 Pill R, French J, Harding K, et al. Invitation to attend a health check in a general practice setting: comparison of attenders and non-attenders. Fournal of the Royal College of General Practitioners 1988;38:53-6.

26 Davies G, Pyke S, Kinmouth A-L. Effect of non-attenders on the potential of a primary care programme to reduce cardiovascular risk in the population. BMF 1994;309: 1553-6. 